\title{
Comparison of the effects of epidural and spinal anesthesia on analgesia and blood gases in neonates born by natural vaginal delivery: A clinical trial study
}

\author{
Soghra Rabiei ${ }^{1}$, Pouran Hajian ${ }^{2}$, Azar Pirdehghan ${ }^{3}$, Khatereh Mabodii ${ }^{4}$, Shahedeh Khansari ${ }^{5, *}$
}

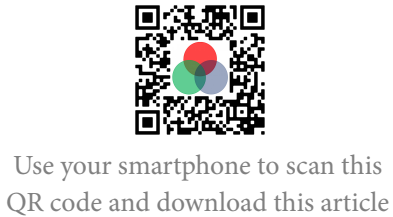

${ }^{1}$ Professor of Obstetrics and Gynecology, School of Medicine, Hamadan University of Medical Sciences, Hamadan, Iran

${ }^{2}$ Assistant Professor of Anesthesiology Department of Anesthesiology, School of Medicine Endometrium and

Endometriosis Research Center, Hamadan University of Medical Sciences, Hamadan, Iran

${ }^{3}$ Associate Professor of Community Medicine, Department of Community Medicine, School of Medicine Health Sciences Research Center, Health Sciences \& Technology Research Institute, Hamadan University of Medical Sciences, Hamadan, Iran

${ }^{4}$ Obstetrician and gynecologist, Department of obstetrics and genecology, Hamadan university of medical sciences, Hamadan, Iran

${ }^{5}$ Obstetrics and Gynecologist, Fatemieh

Hospital, Hamadan, Iran

\section{Correspondence}

Shahedeh Khansari, Obstetrics and Gynecologist, Fatemieh Hospital, Hamadan, Iran

Email: Dr_sh_kh@yahoo.com

History

- Received: Dec 06, 2019

- Accepted: Mar 05, 2020

- Published: Mar 30, 2020

DOI : 10.15419/bmrat.v7i3.595

\section{Check for updates}

\section{Copyright}

(-) Biomedpress. This is an openaccess article distributed under the terms of the Creative Commons Attribution 4.0 International license.

\begin{abstract}
Introduction: One of the concerns of painless deliveries is the safety of neonates. This clinical trial study aimed to compare the effects of epidural and spinal anesthesia on the mortality rate of neonates. Methods: This clinical trial was conducted in Hamadan Hospital in Iran. Ninety women, ages 18 to 45 , were randomly assigned to receive epidural or subdural anesthesia. Using a checklist, the following were collected: demographic information, midwifery, hemodynamic status, mothers' pain intensity, and analyses of the baby's umbilical cord blood. The data were analyzed by SPSS version 16 for statistical analysis. Twenty-two of the patients with spinal anesthesia and epidural anesthesia were excluded from the study. Results: There was no significant difference between the two groups in terms of age, gestational age, parity, and severity of pain before or after anesthesia. The hemodynamic status of the mothers before and during the first postoperative period was in the normal range, except that in the spinal group, a decrease in systolic blood pressure was observed in normal range compared with the epidural anesthesia group. In blood gas analysis, the mean $\mathrm{pH}$, partial pressure of carbon dioxide $\left(\mathrm{PCO}_{2}\right)$, and bicarbonate $\left(\mathrm{HCO}_{3}\right)$ did not show significant differences between the two groups ( $p>0.05$ ). The only complications were acidosis and epidural anesthesia. Conclusion: Based on the findings of the present study, both spinal and epidural opioids have no adverse effects on the health of neonates. However, both spinal and epidural opioid are preferred due to fewer changes in the hemodynamic changes in mothers and in umbilical cord blood gas.
\end{abstract}

Key words: Painless delivery, Spinal anesthesia, Blood gas analysis

\section{INTRODUCTION}

Pregnancy is carried out in a variety of ways which include standard vaginal delivery and cesarean section. Natural childbirth is carried out in two ways- with painless and without pain control. The pain of vaginal delivery is one of the hardest pains that women can experience during their life ${ }^{1}$.

One of the essential methods used to reduce the extent of labor pain in the developed world in recent decades is the use of such local epidural and spinal anesthe$\mathrm{sia}^{2}$.

The pain of vaginal delivery varies widely but many women consider the pain to be unbearable. The pain during pregnancy and vaginal delivery is caused by uterus contractions, cervical enlargement, and stretching of the perinea. The visceral and somatic marker fibers are transmitted to the spinal cord along with sympathetic nervous fibers (via the T10-T12 and L1 nerve impulses) then through the uterus (via T12 and L1 nerve impulses); somatic nerve impulses (S2S4) are transmitted to sacral nerves 2,3 and $4^{3}$.
Various factors affect the perception of delivery; these include duration, anatomy of the mother, size of the embryo, use of oxytocin, prenatal mortality, fear, as well as anxiety from childbirth, behavior, and experience of pain and adaptive systems. The lack of proper control of acute pain is associated with destructive pathophysiologic effects. Moreover, mothers show a higher tendency to lean towards natural delivery, along with pain control, over a cesarean section which is a significant operation ${ }^{4}$.

Inadequate control of labor pain is associated with adverse effects on both the mother and fetus. For example, in the respiratory system, an increase in the respiratory rate resulted from a decrease in uterine and brain blood flow. Lumbar spinal anesthesia is a safe method for the relief of labor pain. Using low amounts of local and narcotic analgesics, lumbar epidural anesthesia is an effective sensory anesthesia in the first stage of delivery (t10-11) and may be needed in the continuation of labor to block completion ${ }^{4}$. 
One of the challenges of local anesthesia (e.g. spinal or epidural) is their effects on the fetus and its hemodynamic status. Epidural anesthesia causes pain reduction, which is associated with increased breathing rate; changes of hemoglobin in the mother can have a negative effect on neonatal hemoglobin ${ }^{5}$.

Regional imbalances may result in uterine contraction by the sympathetic nervous system, although it is a useful effect in delivery. If the sympathetic nerve block is extended, the blood flow rate of the umbilicus can also be reduced ${ }^{6}$. The amount of dissolved oxygen in the fetus falls between 20 to $96 \%$ during labor, and can be considered as a threshold that is associated with fetal distress ${ }^{7}$. A change occurs in $15-24$ $\%$ of the cases in the fetal heart rate after performing a painless method of delivery ${ }^{8}$. Given the lack of studies in the field, as well as lack of policy in the country to promote natural childbirth, this clinical trial study herein was aimed at comparing epidural and spinal anesthesia in newborn babies.

\section{METHODS}

This study herein was a clinical trial study which was carried out at the Hospital in Hamadan (Iran). The study population consisted of 90 patients who had no prior anesthesia.

The inclusion criteria were: first pregnancy or second pregnancy, in an active phase of labor, more than 37 weeks of gestation, single pregnancy, vertex presentation, lack of any underlying disease, women between $18-45$ years of age, as well as pregnant women aged 37 to 42 weeks who attended Fatemieh Hospital (Iran) for normal vaginal delivery and were without control candidates. The exclusion criteria were: use of drugs by patient in operation, unwillingness to participate in the study, and lack of literacy.

Prior to the beginning of the study, all participants had reviewed, agreed to, and provided written consent to participate in the trial. Initially, the technique of work to be done for each patient was explained, accounting for the culture and the patient's level of education. Then, the patients were randomly divided into two groups. For all patients, an intravenous line was taken; at the beginning of the study, 500 to $1000 \mathrm{~mL}$ sodium chloride $0.9 \%$ were infused.

In the spinal patient group, the patient was seated in a sitting position using a-the needle number of 25 spinal needles (Dr. Japan Co Ltd.) and $2 \mathrm{ml}$ of Sufentanil in the subarachnoid area.

In the epidural group, firstly, an empty needle number of 18 (Ogame Turkiye) was inserted into the epidural apace from the interlayer space (L3 and L4) using a loss of resistance method and without using needle tests. Then, the epidural catheter (No 19), $2-3 \mathrm{~cm}$ in space, was inserted. After aspiration and Ensure the catheter is in the epidural space, $12 \mathrm{cc}$ of Bupivacaine $(0.125 \%)$ was injected along with $2 \mathrm{cc}$ of Sufentanil (in the form of Bolus injection). If a patient requested again for analgesia, $8-10 \mathrm{cc}$ of Bupivacaine $(0.125 \%)$ was injected. The patient was put immediately into the supine position, and vital signs were taken, including blood pressure (systolic and diastolic), heart rate before the beginning of drug administration, heart rate at zero minute and every 5 minutes until $15 \mathrm{~min}$ utes, and heart rate every 15 minutes until the birth. The severity of the patient's pain was recorded by the patient according to the Visual Analog Scale (VAS) for pain; the patient was asked to give a degree of pain between 0 to 10 such that a grade of ' 10 ' was the maximum pain the patient could experience.

Immediately after the birth and primary care of the umbilical cord, the umbilical cord blood was taken with a syringe soaked in heparin and was sent to the laboratory in standard conditions for analyzing blood gases.

\section{Randomization}

For this purpose, we used random blocks of 4 . In this way, we used 4 paper sheets on two sheets of letter 1 means spinal and on two sheets of letter 2 means epidural, representing the epidural options. The papers were mixed and placed in a table drawer; each patient was assigned one of the papers randomly and thus assigned to one of the epidural or subdural hematomas. It should be noted that the pages were drawn until all four drawn papers were not selected; they were then returned to the drawer. After the last sheet had been drawn again, the sheets were again returned to the drawer. The above procedure for the next four patients was followed; this sampling method in a row (called consecutive sampling) was done on women who were eligible to enter the study ${ }^{9}$.

The study design involved measurement of the hemodynamic status of patients. According to the study results ${ }^{1}$, and using the statistical software Stata to assess sample size in each group, the study sample size consisted of 45 pregnant women with first or second pregnancy, were in an active phase of labor, were past 37 weeks of gestation, had single pregnancy, had vertex presentation, and lacked of any underlying disease. Contraindications for natural childbirth include placenta previa, breech presentation, transverse presentation, fetus weight more than $4.5 \mathrm{~kg}$, history of cesarean section, and underlying diseases (such as cardiac disease, asthma and/or renal disease). 
Enrollment

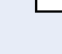

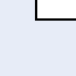

(1)

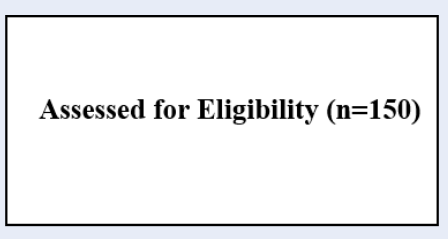

Randomization $(\mathrm{n}=90)$

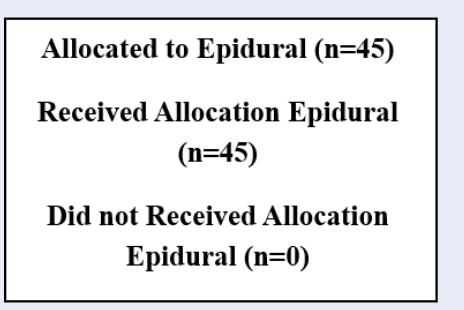

Epidural (n=0)

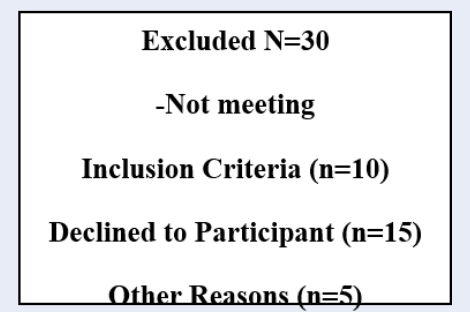

Other Reasons $(n=5)$

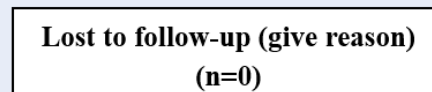

Discontinued Intervention $(n=0)$

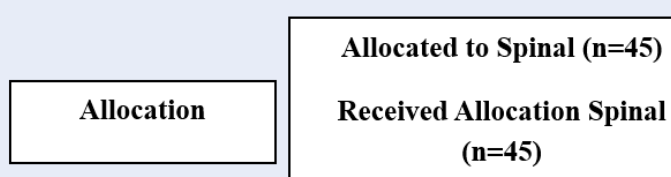

Did not Received Allocation Spinal $(\mathbf{n}=\mathbf{0})$

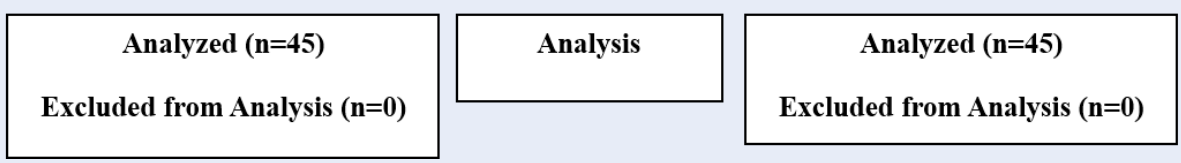

Figure 1: Randomization and participants tracking procedure.

A total number of 90 individuals entered this clinical study (Figure 1). This study was approved by the Committee on Ethics of the Vice-Chancellor of Research and Technology of Hamadan University of Medical Sciences (IR.UMSHA.REC.1397.496).

\section{Data analysis}

Descriptive statistics were carried out; mean and standard deviation were recorded for the quantitative variables, and ratios and percentages were recorded for qualitative variables. In order to compare the relevance of qualitative variables to each other, and quantitative variables, chi-square test (Chi) was used. In this study, SPSS version 16 was used for data analysis. The statistical significance level was set as $\mathrm{P}<0.05$.

\section{Research limitations}

Limitations included the number of patients to participate in this study of the magnitude of pain inten- sity. Pain was based on the patient's judgment. This study was done in coordination with the University of Medical Sciences. Informed consent was obtained from patients before their participation in the study. Whether the patients were referrals to the treatment services or not, there was no effect on diagnosis or treatment. The study data were collected without the inclusion of names and individual characteristics.

The study was conducted in coordination with the University of Medical Sciences. Patients were taken into the study after informed consent. Whether the person visited the university had not impacted on their diagnosis or therapeutics. The study data were collected without listing patient names and individual specifications; the results were generalized.

\section{RESULTS}

In this clinical trial study, 90 pregnant women were nominated for a normal vaginal delivery and with- 
out pain control patients were split into 2 respective groups: epidural (2) and spinal anesthesia (2).

Eleven patients $(12.2 \%)$ of the epidural and spinal groups were excluded from the epidural group due to conditions (e.g. deceleration of fetal heart rate, no failure to the progress of delivery, etc.); in fact, they were excluded from the study. Therefore, 40 patients in the spinal group and 39 patients in the epidural group were monitored and evaluated (Table 1).

It is to noteworthy that in the epidural group, 5 patients (due to arrest of dilatation) and 1 patient (due to fetal distress) underwent cesarean section. Also, in the spinal group, 1 patient (due to arrest) and 4 patients (due to fetal distress) had cesarean sections.

The mean and standard deviation of age in the spinal group and in the epidural group were $23.2 \pm 5.3$ and $22.8 \pm 4.3$, respectively. Comparing the two groups, the average age $(p=0.919)$, pregnancy age $(p=0.430)$, pregnancy number $(\mathrm{p}=0.919)$, and severity of pain before $(p=0.579)$ and after anesthesia $(p=0.189)$ were not significantly different (Table 2 ).

The results of the study showed that before the operation, hemodynamic variables and all other variables across the two groups were comparable. For the patients of the spinal group, blood pressure reduction following the infusion of anesthesia was found to be significant with subdural hematomas, although the changes were not outside the normal range. At other times, the blood pressure of systolic and diastolic in patients with numbness of spinal anesthesia was less than that of epidural; however, there was no significant difference. In both groups, the fetal heart rate and Apgar of neonates were in the normal range and were comparable (Table 3 ).

The findings indicated that the average $\mathrm{pH}$ in the two groups was not statistically significant $(\mathrm{p}=0.313)$ and that the $\mathrm{pH}$ of the groups was in the natural range (7.3). Theoretically, both groups were within the normal range. The mean values of partial pressure of oxygen $\left(\mathrm{PO}_{2}\right)$ of both groups were in the normal range but were less than that for epidural, with a significant difference in the patients ( $\mathrm{p}=0.017$ ) (Table 4).

The findings indicated that there was observed acidosis in only 2 patients, both of them were in the epidural group, and which was not statistically significant ( $\mathrm{p}=$ 0.241) (Tables 3 and 5).

\section{DISCUSSION}

This clinical trial was aimed at comparing the effects of epidural anesthesia and spinal anesthesia on the amount of anesthetics and newborn blood gases in a normal delivery method at an educational center.
The results of the present study showed that painless delivery does not adversely affect the neonates so that the average Apgar coefficient between the two groups in the first and fifth minute was approximately 9 and higher. In the analysis of the umbilical cord blood gases, it was found that the average $\mathrm{pH}$ in the two groups was not statistically significant, and that the blood $\mathrm{pH}$ of the umbilical cord blood was both within the natural range.

The fetal heart rate (FHR) was also normal after the numbness in the normal range, and bradycardia did not occur in neonates. Moreover, there was no effect on the maternal side, and the hemodynamic changes were within the normal range. Both groups of women had a desired state of the condition, and the mean of pain intensity using the VAS scale was approximately $2.5 \%$ after the anesthetic injection at the delivery stage.

In this study, the patients of the 2 groups were studied in terms of parity, age, Apgar score, hemodynamic status of mothers before and after anesthesia, and class. There was found to be no significant differences between the two groups. Therefore, the results of this study cannot be affected by those confounding variables.

The pain of childbirth is one of the hardest pains a woman experiences in her life ${ }^{1}$. Over the years, it has been trying to relieve the pain by taking measures like inhalation of nitrogen $\left(\mathrm{N}_{2}\right)$, acupuncture, hydrography, and use of opium. However, these measures were usually not satisfactory at reducing pain. The introduction of spinal analgesia (epidural and spinal anesthesia, or combination of these two methods) has been one of the most dramatic developments in the control of labor pain, which has been accompanied by maternal satisfaction and the sanctity of the embryo and baby ${ }^{10}$.

Currently, approximately $60 \%$ of women in the United States use painless methods ${ }^{11}$. After spinal cord anesthesia, the heart rate may undergo changes such as those associated with bradycardia. The amount of FHR changes after spinal anesthesia varies between 15 and $25 \%^{12}$. FHR was not used for painless delivery. The patient must be able to provide painless drugs in all delivery stages and have no adverse effects on fetus and neonates, which in the present study; There was no painless effect and there was lack of undesirable effects on the fetus.

Different studies have examined the effects of region on childbirth and its consequences. According to outcome analysis, the type of medicine has been reported for different results from different results. In a case study - evidence in $2010^{13}$, the findings of this study 
Table 1: The status of Normal vaginal delivery and cesarean in patients

\begin{tabular}{lccc}
\hline Childbirth & $\begin{array}{l}\text { Epidural } \\
(\mathbf{n}(\%))\end{array}$ & $\begin{array}{c}\text { Spinal } \\
(\mathbf{n}(\%))\end{array}$ & $p$-value \\
\hline Normal vaginal delivery & $39(86.7)$ & $40(88.9)$ & 0.748 \\
Cesarean & $6(13.3)$ & $5(11.1)$ & \\
Total & $45(100)$ & $45(100)$ & \\
\hline
\end{tabular}

Table 2: A self-administered pain rating system that scores from 1 to 10 patients with severe pain epidural $=45$, spinal $=45$

\begin{tabular}{lccc}
\hline Variable & $\begin{array}{c}\text { Spinal } \\
(\mathbf{M} \pm \mathbf{S D})\end{array}$ & $\begin{array}{c}\text { Epidural } \\
(\mathbf{M} \pm \mathbf{S D})\end{array}$ & $\boldsymbol{p}$-value \\
\hline Age & $23.2 \pm 5.3$ & $22.8 \pm 4.3$ & 0.919 \\
Pregnancy age (week) & $39 \pm 1.4$ & $39.1 \pm 2.4$ & 0.430 \\
Pregnancy number & $1.2 \pm 0.5$ & $1.3 \pm 0.6$ & 0.919 \\
vas (pre - analgesic) & $6.2 \pm 12$ & $6.3 \pm 1.2$ & 0.579 \\
vas (post - analgesic) & $2.6 \pm 0.8$ & $2.6 \pm 1.3$ & 0.187 \\
\hline
\end{tabular}

Table 3: Maternal hemodynamic status, heart rate and Apgar score in both groups

\begin{tabular}{lccc}
\hline Variable & $\begin{array}{c}\text { Spinal } \\
(\mathbf{M} \pm \mathbf{S D})\end{array}$ & $\begin{array}{c}\text { Epidural } \\
(\mathbf{M} \pm \mathbf{S D})\end{array}$ & $p$-value \\
\hline Systolic (pre-analgestic) & $120.3 \pm 4.6$ & $119.3 \pm 7.6$ & 0.319 \\
Diastolic (pre-analgestic) & $68.1 \pm 9.9$ & $66.2 \pm 7.4$ & 0.243 \\
Systolic (post - analgesic) & $117.6 \pm 7.2$ & $122.9 \pm 10.6$ & 0.006 \\
Diastolic (post - analgesic) & $73.2 \pm 9.8$ & $75 \pm 7.9$ & 0.716 \\
Systolic (5 minutes later) & $116.3 \pm 7.6$ & $120.3 \pm 10.1$ & 0.064 \\
Diastolic (5 minutes later) & $73 \pm 9.8$ & $73.6 \pm 7.7$ & 0.767 \\
Systolic (10 minutes later) & $115.2 \pm 9.9$ & $117.1 \pm 10.9$ & 0.370 \\
Diastolic (10 minutes later) & $71.4 \pm 10.2$ & $73.7 \pm 11.1$ & 0.305 \\
Fetal heart rate (pre-analgestic) & $138.9 \pm 4.3$ & $136.7 \pm 6.4$ & 0.121 \\
Fetal heart rate (10 minutes later) & $136.4 \pm 12.1$ & $136.9 \pm 5.2$ & 0.356 \\
Apgar (1 minute later) & $8.9 \pm 0.5$ & $8.9 \pm 0.4$ & 0.789 \\
Apgar (5 minutes later) & $9.9 \pm 0.3$ & $9.9 \pm 0.2$ & 0.697 \\
\hline
\end{tabular}

Table 4: The status for the analysis of neonates blood gases

\begin{tabular}{lccc}
\hline Variable & $\begin{array}{c}\text { Spinal } \\
(\mathbf{M} \pm \mathbf{S D})\end{array}$ & $\begin{array}{c}\text { Epidural } \\
(\mathbf{M} \pm \mathbf{S D})\end{array}$ & $\boldsymbol{p}$-value \\
\hline $\mathrm{PH}$ & $7.3 \pm 0.07$ & $7.3 \pm 0.08$ & 0.313 \\
$\mathrm{PCO}_{2}$ & $40.1 \pm 9.7$ & $42.1 \pm 12.6$ & 0.432 \\
$\mathrm{HCO}_{3}$ & $21.6 \pm 6.1$ & $19.9 \pm 4.4$ & 0.150 \\
$\mathrm{PO}_{2}$ & $19.1 \pm 11.9$ & $24.8 \pm 16.5$ & 0.017 \\
Base Deficit & $3.3 \pm 2.6$ & $3.4 \pm 2.5$ & 0.576 \\
Hematocrit & $44.4 \pm 8.1$ & $43.6 \pm 7.7$ & 0.666 \\
\hline
\end{tabular}


Table 5: The condition of blood gases in the patients of the two studied groups

\begin{tabular}{lccc}
\hline Condition & $\begin{array}{c}\text { Spinal } \\
(\mathbf{m g} / \mathbf{d l})\end{array}$ & $\begin{array}{l}\text { Epidural } \\
(\mathbf{m g} / \mathbf{d l})\end{array}$ & $\boldsymbol{p}$-value \\
\hline Acidosis & - & $2(5.1)$ & 0.241 \\
Normal & $40(100.0)$ & $437(94.8)$ & \\
Total & $40(100.0)$ & $39(100.0)$ & \\
\hline
\end{tabular}

revealed that the rate section, umbilical cord blood gases, Apgar scores, and baby outcome in anesthesia patients confirm the findings of this study.

Moreover, the results of another study ${ }^{14}$ showed that patients with epidural anesthesia were not abnormal, even in the first half hours after the administration of anesthetia. In another study, a relatively small sample volume of low sample size has been carried out from the epidural - spinal method with significant changes of painless childbirth. It was also observed that after the numbness of significant changes (such as in the heart rate of the embryo), the incidence of bradycardia aligns with the findings of the present study.

Reynolds et al., in a study, found that Epichlorohydrin would reduce the blood pressure of the mother and fever, as well as increase in the second stage of labor and the use of a vacuum for the birth of vaginal delivery. However, the latter duty is negligible in the face of the risk reduction of acidosis in neonates ${ }^{15}$. In the present study, there were only $5 \%$ of patients who had acidosis and who did not pose as a serious threat to the neonates. It has been shown if the epidural is not carried out at the right time, it may be accompanied by a cesarean section risk ${ }^{13}$. In this study, $10-$ $13 \%$ in both groups eventually had cesarean sections; of these, there were $83 \%$ in the epidural and $20 \%$ in the spinal group due to arrest dilatation. In fact, the epidural group (17\%) and the spinal group (80\%) experienced fetal distress which led to cesarean section. In a study published in the Cochran database, the epidural is accompanied by an increase in the second phase of labor and a cesarean section risk ${ }^{16}$. Considering that the conventional method for low sample size is the epidural or spinal anesthesia, most studies have examined these techniques, although the spinal technique may also be widely used due to neurological sequels ${ }^{17}$.

One of the advantages of epidural analgesia is that it reduces the need for systemic drugs that may result in neonatal respiratory depression. On the other hand, pain reduction leads to a decrease in the endogenous opioid secretion. The advantage of epidural injection is the possibility of a sensory block without motor block, and minimum hemodynamic complications, and reducing catecholamines. In the present study, hemodynamic changes in the epidural group were less than those for the spinal group.

On the other hand, people are also considering health and treatment policies. These are based on the fact that elective cesarean can be reduced and one of the women worries to have normal vaginal delivery. However, the women are associated with it since it is has been determined that this method is accompanied by pain relief and lack of serious complications.

\section{CONCLUSIONS}

According to the findings of this study, both the spinal and epidural methods have adverse effects on infant health. However, given that the epidural induces fewer changes to hemodynamics and maternal umbilical cord blood gas low sample size.

\section{ABBREVIATION}

FHR: Fetus Heart Rate

VAS: Visual Analog Scale

\section{AOUTHORS' CONTRIBUTIONS}

All authors contributed equally in the study design, interpretation of the data and writing of the final manuscript.

\section{COMPETING INTERESTS}

The author(s) declare that they have no competing interests.

This study was supported by Hamadan University of Medical Sciences.

\section{ACKNOWLEDGMENTS}

We thank the manager of Fatemieh hospital and also participants to participate in this study.

\section{REFERENCES}

1. Melzack R. The myth of painless childbirth (the John J Bonica lecture). Pain. 1984;19:321-337. PMID: 6384895. Available from: https://doi.org/10.1016/0304-3959(84)90079-4. 
2. Konefal H, Jaskot B, Czeszynska M. Pethidine for labor analgesia; monitoring of newborn heart rate, blood pressure and oxygen saturation during the first 24 hours after the delivery. Epub 2012/06/20. Petydyna w analgezji porodu; monitorowanie czynnosci serca, cisnienia tetniczego i saturacji w ciagu pierwszych 24 godzin zycia noworodka. pol. Ginekol Pol. 2012;83(5):357-362. PMID: 22708333.

3. Miller R, Eriksson L, Fliesher L. Winer-Kronish JP. Miller's anesthesia. 6 ed. New York: McGraw-Hill. 2005.

4. Rolfseng O, Skogvoll E, Borchgrevink P. Epidural bupivacaine with sufentanyl or fentanyl during labour, a randomized double blind study. Eurk J Anesthesiol. 2002;19(11):812818. PMID: 12442931. Available from: https://doi.org/10.1097/ 00003643-200211000-00007.

5. Scherer R, Holzgreve W. Influence of epidural analgesia on fetal and neonatal well-being. Eur J Obstet Gynecol Reprod Biol. 1995;59:17-29. PMID: 7556818. Available from: https: //doi.org/10.1016/0028-2243(95)93909-8.

6. Eberle R, Norris M, Eberle A, Naulty J, Arkoosh V. The effect of maternal position on fetal heart rate during epidural or intrathecal labor analgesia. Am J Obstet Gynecol . 1998;179:150-155. PMID: 9704781. Available from: https: //doi.org/10.1016/S0002-9378(98)70266-2.

7. Goffinet F, Langer B, Carbonne B. Multicenter study on the clinical value of fetal pulse oximetry. I. Methodologic evaluation.The French Study Group on Fetal Pulse Oximetry. Am J Obstet Gynecol. 1997;177:1238-1246. PMID: 9396924. Available from: https://doi.org/10.1016/S0002-9378(97)70045-0.

8. Palmer C, Maciulla J, Cork R, Nogami W, Gossler K, Alves D. The incidence of fetal heart rate changes after intrathecal fentanyl labor analgesia. Anesth Analg. 1999;88:577-581. PMID: 10072009. Available from: https://doi.org/10.1213/00000539199903000-00021.

9. Caliskan E, Ozdamar D, Doger E, Cakiroglu Y, A K, Corakci A. Prospective case control comparison of fetal intrapartum oxygen saturations during epidural analgesia. Int J Obstet Anesth. 2010;19(1):77-81. PMID: 19945845. Available from: https: //doi.org/10.1016/j.ijoa.2009.04.012.

10. Hawkins J, Gibbs C, Orleans M, et al. Obstetric anesthesia work force survey, 1981 versus 1992. Anesthesiology . 1997;87:135-
143. PMID: 9232144 . Available from: https://doi.org/10.1097/ 00000542-199707000-00018PMid:9232144.

11. Grant E, Tao W, Craig M, McIntire D, Leveno K. Neuraxial analgesia effects on labour progression: facts, fallacies, uncertain ties and the future. BJOG : an international journal of obstetrics and gynaecology. 2015;122(3):288-293. PMID: 25088476. Available from: https://doi.org/10.1111/1471-0528.12966.

12. Palmer C, Maciulla J, Cork R, Nogami W, Gossler K, Alves D. The incidence of fetal heart rate changes after intrathecal fentanyl labor analgesia. Anesth Analg. 1999;88:577-581. PMID: 10072009. Available from: https://doi.org/10.1213/00000539199903000-00021.

13. Zhang J, Landy H, Branch D, Burkman R, Haberman S, Gregory K, et al. Contemporary patterns of spontaneous labor with normal neonatal outcomes. Obstetrics and Gynecology. 2010;116(6):1281-1287. PMID: 21099592. Available from: https://doi.org/10.1097/AOG.0b013e3181fdef6e.

14. Caracostea G, Stamatian F, Lerintiu M, Herghea D. The influence of maternal epidural analgesia upon intrapartum fetal oxygenation. J Matern Fetal Neonatal Med. 2007;20(2):161165. PMID: 17437215. Available from: https://doi.org/10.1080/ 14767050601134561

15. Reynolds F, Sharma S, Seed P. Analgesia in labour and fetal acid-base balance: a meta-analysis comparing epidural with systemic opioid analgesia. BJOG : an international journal of obstetrics and gynaecology. 2002;109(12):1344-1353. PMID: 12504969. Available from: https://doi.org/10.1046/j. 1471-0528.2002.01461.x.

16. Anim-Somuah M, Smyth R, Jones L. Epidural versus nonepidural or no analgesia in labour (Review). The Cochrane Database of Systematic Reviews. 2011;12 CD000331. PMID: 22161362. Available from: https://doi.org/10.1002/14651858 CD000331.pub3.

17. Hattler J, Klimek M, Rossaint R, Heesen M. The Effect of Combined Spinal-Epidural Versus Epidural Analgesia in Laboring Women on Nonreassuring Fetal Heart Rate Tracings: Systematic Review and Meta-analysis. 2016;123(4):955-964. PMID: 27509225. Available from: https://doi.org/10.1213/ ANE.0000000000001412. 